Article

\title{
Preparation, Characterization, and Pharmacokinetic Evaluation of Imperatorin Lipid Microspheres and Their Effect on the Proliferation of MDA-MB-231 Cells
}

\author{
Xinli Liang ${ }^{\circledR}$, Xulong Chen, Guowei Zhao, Tao Tang, Wei Dong, Chunyan Wang, Jing Zhang $(\mathbb{D}$ \\ and Zhenggen Liao * \\ Key Laboratory of Modern Preparation of Traditional Chinese Medicine, Jiangxi University of Traditional \\ Chinese Medicine, Nanchang 330004, China; Paln7@163.com (X.L.); cx10517@163.com (X.C.); \\ weiweihaoyunqi@163.com (G.Z.); marryrose1013@163.com (T.T.); sober96@foxmail.com (W.D.); \\ doscat@163.com (C.W.); evens_zhang@163.com (J.Z.) \\ * Correspondence: lyzlyg@163.com; Tel.: +86-791-87118658
}

Received: 13 October 2018; Accepted: 8 November 2018; Published: 16 November 2018

\begin{abstract}
Imperatorin is a chemical compound belonging to the linear furanocoumarins. Imperatorin is attracting considerable attention because of its antitumor, antibacterial, anti-inflammatory, and anticoagulant activities, inhibition of myocardial hypertrophy, and other pharmacological efficacies. However, imperatorin has limited water solubility and has better lipid solubility; thus, we decided to design and synthesize imperatorin lipid microspheres to optimize the preparation conditions. The aim was to develop and formulate imperatorin lipid microspheres through nanoemulsion technology and apply the response surface-central composite design to optimize the imperatorin lipid microsphere formulation. The influence of the amounts of egg lecithin, poloxamer 188, and soybean oil for injection on the total percentage of the oil phase was investigated. The integrated effect of dependent variables, including particle size, polydispersity index, zeta potentials, drug loading, and encapsulation efficiency, was investigated. Data of overall desirabilities were fitted to a second-order polynomial equation, through which three-dimensional response surface graphs were described. Optimum experimental conditions were calculated by Design-Expert 8.06. Results indicated that the optimum preparation conditions were as follows: $1.39 \mathrm{~g}$ of egg lecithin, $0.21 \mathrm{~g}$ of poloxamer 188, and $10.57 \%$ soybean oil for injection. Preparation of imperatorin lipid microspheres according to the optimum experimental conditions resulted in an overall desirability of 0.7286 , with the particle size of $168 \pm 0.54 \mathrm{~nm}$, polydispersity index (PDI) of $0.138 \pm 0.02$, zeta potentials of $-43.5 \pm 0.5 \mathrm{mV}$, drug loading of $0.833 \pm 0.27 \mathrm{mg} \cdot \mathrm{mL}^{-1}$, and encapsulation efficiency of $90 \pm 1.27 \%$. The difference between the observed and predicted values of the overall desirability of the optimum formulation was in the range from $2.4 \%$ to $4.3 \%$. Subsequently, scanning electron microscopy was used to observe the micromorphology of the imperatorin lipid microspheres, showing round globules of relatively uniform shape and sizes within $200 \mathrm{~nm}$. The effect of imperatorin lipid microspheres on MDA-MB-231 proliferation was investigated by the MTT method. Furthermore, pharmacokinetics in Sprague-Dawley rats was evaluated using orbital bleeding. A sensitive and reliable liquid chromatography with the high-performance liquid chromatography (HPLC) method was established and validated for the quantification of imperatorin in rat plasma samples. The data were calculated by DAS (drug and statistics) Pharmacokinetic Software version 3.3.0 (Version 3.3.0, Shanghai, China). Results demonstrated that imperatorin lipid microspheres can significantly enhance the bioavailability of imperatorin and can significantly inhibit MDA-MB-231 cell proliferation. In conclusion, our results suggested that the response surface-central composite design is suitable for achieving an optimized lipid microsphere formulation. Imperatorin lipid microspheres can improve the bioavailability of imperatorin and better inhibit the proliferation of MDA-MB-231 cells as compared to imperatorin alone.
\end{abstract}


Keywords: imperatorin; lipid microsphere; response surface methodology; pharmacokinetic

\section{Introduction}

Imperatorin is a chemical compound belonging to the linear furanocoumarins and it is mainly extracted and isolated from the traditional herbal medicine of Angelica dahurica. Modern pharmaceutical studies have identified that imperatorin has good biological activity, including analgesic, antibacterial, anti-inflammatory, vessel dilating, and CYP450-inhibiting effects [1]. Many studies have suggested that imperatorin had certain antitumor efficacies, such as an inhibiting effect on a human hepatocellular carcinoma cell line, a human breast cancer cell line, a human cervical carcinoma cell line, a human osteosarcoma cell line, and other metastatic tumor cells. The mechanism mainly included a downregulating effect on mitochondrial $\mathrm{MCl}-1$ protein expression [2-5]. Jakubowicz-Gil showed that imperatorin combined with quercetin could effectively inhibit the proliferation of tumor cells and induce the cells' apoptosis [6-8]. These findings suggested that imperatorin is a potential anticancer drug with a good application prospect. So, it is obvious that the compound has great potential to be developed as a pharmaceutical formulation for subsequent clinical assessment. But, Imperatorin belongs the BCS II classfication system. It shows a relatively low bioavailability because of its poor water solubility [9]. So, it is difficult to prepare an ideal oral pharmaceutical preparation [10]. It is more difficult to be developed as an injection. Research reports ultradeformable liposomes as a novel vesicular carrier could increase skin permeation efficiency of imperatorin [11], and Jingjing Pan prepared imperatorin sustained-release tablets to lower blood pressure [12]. There is no injection of imperatorin reported. In this study, we took advantage of imperatorin's characteristics of poor solubility in water and good fat solubility and dissolved it in an oil-based injection, selected lecithin as an emulsifier, and used nanoemulsification technology to prepare imperatorin lipid microspheres.

Lipid microsphere (LM) has been recently used as intravenous (i.v.) carriers for drugs, especially for those drugs that have enough solubility in oil while have poor solubility in water. It is difficult for this kind of drugs to prepare injection preparations. The LM, with a diameter of 0.2 microns, is composed of soybean oil and lecithin, can carry lipophilic or hydrophilic drugs, drugs are usually incorporated into the oil phase or into the interface of oil phase in LM, so they are presumed to avoid or reduce local or blood vessel irritation. As a lipophilic drug carrier, it has the following advantages of targeting positioning, improving the solubility and stability of drugs, reducing the adverse reactions, etc. [13,14].

Uniform design and orthogonal design are two kinds of experimental design methods that are widely used in the research of pharmaceutical preparations of Chinese herbal medicines [15]. However, the uniform design and orthogonal design optimization method is constrained by the linear model, as it can only point out the direction of factor values and is unable to find extremes, and the deviation between the measured and predicted values is larger under the optimum preparation conditions [16]. Response surface methodology (RSM) is a combination of mathematical and statistical techniques, which has the characteristics of requiring fewer tests and having higher test accuracy. It is also more simplified and comprehensive than orthogonal design and uniform design. In the process of optimization, practical research mainly focuses on central composite design (CCD) under RSM [17]. Because CCD is very practically suitable for comparing experimental methodologies with theoretical models [18], and it includes not only the effects of interaction of the variables but also the overall effects of the parameters in the process [19], it is often used in the optimization method for the preparation of new technologies.

Breast cancer is one of the most common female cancers in the world. It is still associated with high morbidity and mortality. At present, chemotherapy and surgery are the most important methods of treating breast cancer. Imperatorin is a single component of some traditional Chinese medicines, which has the characteristics of high efficacy and low toxicity. Previous studies have showed that imperatorin has an antitumor effect $[20,21]$, and it has a strong inhibitory effect on 
MDA-MB-231 cells [22]. However, because of its physical and chemical properties, its druggability is very low. In order to increase its druggability and to exert its antitumor effect, the optimization of the preparation and formulation of imperatorin lipid microspheres was accomplished; furthermore, the pharmacokinetics of imperatorin in rats was investigated, and the respective effects of imperatorin and imperatorin lipid microspheres on MDA-MB-231 cell proliferation were also compared in the study.

\section{Materials and Methods}

\subsection{Materials}

\subsubsection{Chemicals and Drugs}

Imperatorin was purchased from the National Institutes for Food and Drug Control (batch: 110826-200511, Beijing, China). Soybean oil for injection (long-chain triglyceride, LCT) and medium-chain fatty acid glyceride for injection (MCT) were purchased from Tieling North Asia Medicinal Oil Co. Ltd. (Tieling, China). Egg lecithin was purchased from Dongshang biotechnology Co. Ltd. (Shanghai, China). Glycerol for injection was purchased from the Jiangxi Benefit Spectrum Health Pharmaceutical Division (Nanchang, China). Poloxamer 188 was purchased from Shanghai Changsheng Technology Co. Ltd. (Shanghai, China). The reagents were chromatographically and analytically pure.

Fetal calf serum (FCS) and RPMI1640 were purchased from Hyclone (Thermo Fisher Scientific). Penicillin and streptomycin solutions $(10,000 \mathrm{U} / \mathrm{mL}$ penicillin and $10,000 \mathrm{mg} / \mathrm{mL}$ streptomycin) were purchased from Solarbio (Beijing Solarbio Science \& Technology Co., Ltd., Beijing, China). Nonessential amino acids were obtained from Sigma Chemical Co. (St. Louis, MA, USA). Trypsin-EDTA solution $(0.25 \%(w / w)$ trypsin/1 mM EDTA) was supplied by Gibco Laboratories (Life Technologies Inc., Carlsbad, CA, USA). MTT cell proliferation and Cytotoxicity Detection Kit (batch: 20170613) were purchased from Jiangsu KeyGEN BioTECH Corp., Ltd. (Nanjing, China). MDA-MB-231 cells were purchased from the cell bank of the Chinese Academy of Sciences.

\subsubsection{Animals}

Male Sprague-Dawley (SD) rats were purchased from Slack King Experimental Animal Center in Hunna (Hunan, Changsha, China). Before the experiment, all rats were housed in an environmentally controlled room $\left(25 \pm 2{ }^{\circ} \mathrm{C}\right.$ and relative air humidity $\left.52 \pm 20 \%\right)$ with free access to food and water. All animal experiments were approved by the Animal Center Committee of Jiangxi University of Traditional Chinese Medicine, all of which were conducted in full compliance with the local, national, ethical, and regulatory principles.

\subsection{Methods}

\subsubsection{Imperatorin Lipid Microsphere Preparation}

Imperatorin lipid microspheres were prepared with a high-speed shearing and high-pressure homogenization method, as described previously $[23,24]$. Imperatorin was dissolved in the oil phase, which was composed of egg yolk lecithin, LCT, and MCT. The water phase was composed of glycerol, sodium oleate, and poloxamer 188 . The oil phase and water phase were both heated to $70^{\circ} \mathrm{C}$, and then the hot oil phase was added to the water phase and stirred in a high-speed shearing homogenizer for $10 \mathrm{~min}$ at a revolution speed of $19,000 \mathrm{rpm}$ to obtain the colostrum. Thereafter, the colostrum was circulated six times at 600 bar in the homogenizer, after which imperatorin lipid microspheres were obtained.

\subsubsection{Measurement of Size, PDI, and Zeta Potential of Imperatorin Lipid Microsphere}

The average particle size, PDI, and zeta potential of the lipid microspheres were measured while using a Malvern laser particle size analyzer (Mal-vern, UK). Samples were diluted appropriately with double-steamed water for the measurements, and zeta potential measurements were detected at $25^{\circ} \mathrm{C}$. 


\subsubsection{Scanning Electron Microscopy (SEM)}

The morphologies of the imperatorin lipid microspheres and blank lipid microspheres were observed using a FEIQuanta 250 SEM (FEI Corporation, Hillsboro, OR, USA). After dilution with double-steamed water, a drop of solution was placed on the sample stand, was drained naturally, and was sprayed for observation.

\subsubsection{Determination of Drug Loading and Encapsulation Efficiency}

Encapsulation efficiency was determined by ultra-high-speed centrifugation. In addition, the drug loading and encapsulation efficiency of imperatorin was determined following the solubilization of carriers in methanol and analysis by the high-performance liquid chromatography (HPLC) method. The mobile phase consisted of methanol and double-distilled water $(80: 20, v / v)$. A volume of $20 \mu \mathrm{L}$ of sample was injected and the flow rate was $1 \mathrm{~mL} / \mathrm{min}$. The column temperature was maintained at $25^{\circ} \mathrm{C}$ and the detection wavelength was set at $330 \mathrm{~nm}$ [25].

The drug loading was calculated according to the standard curve [26]

$$
\begin{gathered}
\text { Encapsulation efficiency }(\%)=\left(C_{\mathrm{o}} \mathrm{V}_{\mathrm{o}}-\mathrm{C}_{\mathrm{w}} \mathrm{V}_{\mathrm{w}}\right) / \mathrm{C}_{\mathrm{o}} \mathrm{V}_{\mathrm{o}} \times 100 \% \\
\text { Drug loading }=\left(\mathrm{C}_{\mathrm{a}} \mathrm{W}_{\mathrm{b}}\right) / \mathrm{W}_{\mathrm{a}}
\end{gathered}
$$

\subsubsection{RSM Design and Optimization of Imperatorin Lipid Microsphere Preparation Conditions}

RSM was developed to acquire the optimal preparation conditions by establishing the relationships between the variables and the response.

Based on the single factor test results of preliminary experiments and our previous studies, three formulation parameters, namely the amounts of egg lecithin (A), poloxamer 188 (B), and soybean oil for injection, accounting for the total percentage of the oil phase (C), were identified as the key factors that are responsible for the particle size $\left(\mathrm{Y}_{1}\right)$, polydispersity index $\left(\mathrm{Y}_{2}\right)$, zeta potential $\left(\mathrm{Y}_{3}\right)$, drug loading $\left(\mathrm{Y}_{4}\right)$, and encapsulation efficiency $\left(\mathrm{Y}_{5}\right)$. The range and levels of the three independent variables used in this study is summarized in Table 1 . The central composite design experiments were carried out in a randomized order, which included six repeated experiments to eliminate the system error. Dependent variables or responses were transformed into desirabilities mathematically by Hassan's method. Overall desirability was calculated from the geometric mean of five desirabilities of each formulation. In this method, we set the best value as 1 and the worst value as 0 , and all desirabilities are normalized from 0 to 1 .

Table 1. Levels and code of variables chosen for the central composite design.

\begin{tabular}{ccccccc}
\hline \multirow{2}{*}{ Factors } & \multirow{2}{*}{ Code } & \multicolumn{7}{c}{ Range and Levels } \\
\cline { 3 - 7 } & & $\mathbf{- 1 . 7 3 2}$ & $\mathbf{- 1}$ & $\mathbf{0}$ & $\mathbf{1}$ & $\mathbf{1 . 7 3 2}$ \\
\hline egg lecithin & $\mathrm{A}$ & 1 & 1.11 & 1.25 & 1.39 & 1.5 \\
Poloxamer 188 & $\mathrm{B}$ & 0.1 & 0.21 & 0.35 & 0.49 & 0.6 \\
Soybean oil/oil phase & $\mathrm{C}$ & 0 & 10.57 & 25.00 & 39.43 & 50 \\
\hline
\end{tabular}

The formula to calculate the overall desirability was expressed as follows [27]:

$$
\begin{gathered}
O D=\left(d_{1} d_{2} d_{3} d_{4} d_{5}\right)^{1 / 5} \\
d_{\min }=\left(Y_{\max }-Y_{i}\right) /\left(Y_{\max }-Y_{\min }\right) \\
d_{\max }=\left(Y_{i}-Y_{\min }\right) /\left(Y_{\max }-Y_{\min }\right)
\end{gathered}
$$

where $d$ is the overall desirability of each independent variable; $d_{1}, d_{2}, d_{3}, d_{4}$, and $d_{5}$ are the overall desirabilities of particle size, particle size distribution, zeta potential, drug loading, and encapsulation 
efficiency, respectively; $Y$ is the determination value of each independent variable $(i=1,2,3,4,5)$; and, $Y_{\max }$ and $Y_{\min }$ are the maximum and minimum, respectively, of each independent variable in all the tests.

Design-Expert 8.0 software was used to analyze the experimental data of overall desirabilities, perform multiple regressions to obtain the coefficients of the cubic polynomial model, and to obtain the three-dimensional response surface graphs. The quality of the fitted model was expressed by the coefficient of determination $\mathrm{R}^{2}$, and its statistical significance was determined by the $F$-test.

\subsubsection{Pharmacokinetics and Statistical Analysis}

Six male Sprague-Dawley rats were given imperatorin lipid microspheres $\left(1 \mathrm{mg} \cdot \mathrm{mL}^{-1}\right)$ by the means of IV at a dose of $5 \mathrm{mg} / \mathrm{kg}$. Orbital blood samples $(200 \mu \mathrm{L})$ were collected at 2, 5, 10, 15, 20, $30,45,60,90,120,180,240$, and $360 \mathrm{~min}$ after administration. Six male Sprague-Dawley rats were given imperatorin suspensions (dissolved in appropriate amount DMSO) by the means of intragastric administration at a dose of $50 \mathrm{mg} / \mathrm{kg}$. Orbital blood samples (200 $\mu \mathrm{L})$ were collected at 2, 10, 20, $30,40,50,60,90,120,180,240,360,480$, and $600 \mathrm{~min}$ after oral administration. Blood samples were placed in heparinized tubes and immediately centrifuged in a centrifuge tube coated with sodium heparin at $4000 \mathrm{rmp} \cdot \mathrm{min}^{-1}$ at $4{ }^{\circ} \mathrm{C}$ for $10 \mathrm{~min}$. The supernatant was taken and stored at $-80{ }^{\circ} \mathrm{C}$ until further analysis.

Plasma samples were treated by a liquid-liquid extraction method. $100 \mu \mathrm{L}$ of plasma samples (containing internal standard oxypeucedanin) and $900 \mu \mathrm{L}$ of methanol were placed in a $1.5 \mathrm{~mL}$ of Eppendorf tube. Samples were then vortex-mixing for $3 \mathrm{~min}$ and centrifuged for $30 \mathrm{~min}$ at 16,000 rmp. Approximately, $1 \mathrm{~mL}$ of supernatant was placed into another clean tube and filtered with $0.22 \mu \mathrm{m}$ filter.

Samples were analysed by using a HPLC (Aglient 1260, Agilent Technology, Santa Clara, CA, USA). The chromatographic conditions are as follows: Phenomenex- $\mathrm{C}_{18}(4.6 \mathrm{~mm} \times 250 \mathrm{~mm}, 5 \mu \mathrm{m})$; the mobile phase consisted of methanol and double distilled water (80:20,v/v), A volume of $20 \mu \mathrm{L}$ of sample was injected, and the flow rate was $1 \mathrm{~mL} / \mathrm{min}$. The column temperature was maintained at $25{ }^{\circ} \mathrm{C}$ and the detection wavelength was set at $330 \mathrm{~nm}$ [21].

Pharmacokinetic parameters of imperatorin after intravenous injection of imperatorin lipid microsphere were calculated by Software version 3.3.0 (Shanghai, China).

\subsubsection{Effect of Imperatorin and Imperatorin Lipid Microspheres on MDA-MB-231 Cell Proliferation}

MDA-MB-231 cells were cultured in medium containing RPMI1640 (10\% fetal bovine serum, $1 \%$ nonessential amino acids, $1 \%$ L-glutamine, $100 \mathrm{U} / \mathrm{mL}$ penicillin-streptomycin). The cells were maintained at $37{ }^{\circ} \mathrm{C}$ in an atmosphere containing $5 \% \mathrm{CO}_{2}$ at $95 \%$ relative humidity. The medium was changed every other day during cell growth and differentiation. The cells could be used in the experiments when they had grown to $80-90 \%$. The cells were seeded onto 96 -well plates at a density of $5 \times 10^{4}$ and supernatant was discarded after $24 \mathrm{~h}$ of growth. Different concentrations of imperatorin and imperatorin lipid microspheres were added to the cells and cells were subsequently cultured for different amount of time $(24,48$, and $72 \mathrm{~h})$, according to the instructions of the MTT cell proliferation and cytotoxicity test kit, to study the effect of imperatorin and imperatorin lipid microspheres on MDA-MB-231 cell proliferation.

$$
\text { Inhibition of cell proliferation }(\%)=\frac{\text { Control group OD }- \text { Drug group OD }}{\text { Control group OD }} \times 100 \%
$$

\subsection{Data Analysis}

All experimental data in this experiment were expressed as the mean \pm standard error. Data analyses were performed by using the DAS 3.3.0 pharmacokinetic program (Chinese Pharmacology Society, Shanghai, China). All statistical analyses were analyzed using Student's $t$-test. 


\section{Results and Discussion}

\subsection{Central Composite Design of Response Surface Methodology}

The experimental data are summarized in Table 2. The statistical significance of the regression model was analyzed by $p$-value and F-test, and the analysis of variance (ANOVA) for the response surface quadratic model is shown in Table 3 , in which the $p$-values $<0.01$ implied the model was very significant, and $p$-values $<0.05$ suggested the model term was significant. The $p$-value for the "Lack of Fit" test was 1.78, indicating that the quadratic model was adequate.

Table 2. Variables and observed responses in the central composite design for imperatorin lipid microspheres.

\begin{tabular}{|c|c|c|c|c|c|c|c|c|c|}
\hline \multicolumn{10}{|c|}{ No. Levels of Independent Factors' Responses } \\
\hline & A & B & $\mathrm{C}$ & $\mathrm{Y}_{1}$ & $\mathrm{Y}_{2}$ & $\mathrm{Y}_{3}$ & $\mathbf{Y}_{4}$ & $Y_{5}$ & OD \\
\hline 1 & 1.11 & 0.21 & 39.43 & 177 & 0.148 & -43.4 & 6.58 & $89 \%$ & 0 \\
\hline 2 & 1.25 & 0.35 & 25.00 & 172 & 0.131 & -44.1 & 7.59 & $90 \%$ & 0.4835 \\
\hline 3 & 1.11 & 0.49 & 10.57 & 169 & 0.168 & -47.0 & 8.27 & $89 \%$ & 0.5195 \\
\hline 4 & 1.25 & 0.35 & 25.00 & 172 & 0.128 & -43.7 & 7.72 & $88 \%$ & 0.4582 \\
\hline 5 & 1.25 & 0.35 & 25.00 & 161 & 0.138 & -45.0 & 7.29 & $89 \%$ & 0.4562 \\
\hline 6 & 1.39 & 0.49 & 39.43 & 164 & 0.097 & -38.7 & 6.93 & $81 \%$ & 0 \\
\hline 7 & 1.25 & 0.35 & 25.00 & 165 & 0.148 & -43.5 & 7.23 & $90 \%$ & 0.4013 \\
\hline 8 & 1.25 & 0.35 & 0 & 167 & 0.129 & -43.4 & 7.16 & $84 \%$ & 0.3693 \\
\hline 9 & 1.11 & 0.21 & 10.57 & 193 & 0.122 & -45.2 & 9.43 & $91 \%$ & 0 \\
\hline 10 & 1.0 & 0.35 & 25.00 & 201 & 0.132 & -43.9 & 9.02 & $89 \%$ & 0 \\
\hline 11 & 1.5 & 0.35 & 25.00 & 168 & 0.134 & -43.8 & 7.33 & $88 \%$ & 0.4629 \\
\hline 12 & 1.39 & 0.49 & 39.43 & 177 & 0.183 & -41.9 & 9.14 & $89 \%$ & 0.5391 \\
\hline 13 & 1.39 & 0.49 & 10.57 & 154 & 0.116 & -44.5 & 8.28 & $81 \%$ & 0 \\
\hline 14 & 1.11 & 0.49 & 39.43 & 165 & 0.094 & -42.4 & 7.29 & $88 \%$ & 0.4037 \\
\hline 15 & 1.39 & 0.21 & 10.57 & 168 & 0.138 & -43.5 & 8.33 & $90 \%$ & 0.7286 \\
\hline 16 & 1.25 & 0.35 & 25.00 & 164 & 0.120 & -43.5 & 7.76 & $89 \%$ & 0.6020 \\
\hline 17 & 1.25 & 0.35 & 50.00 & 176 & 0.136 & -44.7 & 7.88 & $90 \%$ & 0.4567 \\
\hline 18 & 1.25 & 0.35 & 25.00 & 170 & 0.129 & -43.1 & 10.42 & $90 \%$ & 0.6491 \\
\hline 19 & 1.25 & 0.1 & 25.00 & 196 & 0.097 & -41.5 & 10.92 & $92 \%$ & 0.4569 \\
\hline 20 & 1.25 & 0.6 & 25.00 & 170 & 0.096 & -40.5 & 9.27 & $93 \%$ & 0 \\
\hline
\end{tabular}

Table 3. Statistical analysis of variance for the experimental results.

\begin{tabular}{cccccc}
\hline Source & Sum of Squares & df & Mean Square & $\boldsymbol{F}$ Value & $p$-Value Prob > 7 \\
\hline Model & 1.05 & 9 & 0.12 & 9.16 & $0.0009^{*}$ \\
A-A & 0.094 & 1 & 0.094 & 7.36 & 0.0218 \\
B-B & 0.092 & 1 & 0.092 & 7.23 & 0.0228 \\
C-C & $1.691 \times 10^{-3}$ & 1 & $1.691 \times 10^{-3}$ & 0.13 & 0.7233 \\
AB & 0.60 & 1 & 0.60 & 108.14 & $<0.0001$ \\
AC & $6.778 \times 10^{-4}$ & 1 & $6.778 \times 10^{-4}$ & 0.053 & 0.8223 \\
BC & $6.778 \times 10^{-4}$ & 1 & $6.778 \times 10^{-4}$ & 0.053 & 0.8223 \\
A $^{2}$ & 0.14 & 1 & 0.14 & 11.28 & 0.0073 \\
B $^{2}$ & 0.15 & 1 & 0.15 & 11.52 & 0.0068 \\
C $^{2}$ & 0.019 & 1 & 0.019 & 1.52 & 0.2462 \\
Residual & 0.13 & 10 & 0.013 & & 0.2713 \\
Lack of Fit & 0.082 & 5 & 0.016 & 1.78 & \\
Pure Error & 0.046 & 5 & $9.174 \times 10^{-3}$ & & \\
Cor Total & 1.18 & 19 & & &
\end{tabular}


After statistical processing and fitting, multiple regression equations were obtained, as follows: Final equation in terms of coded factors:

$$
\begin{gathered}
\mathrm{OD}=0.51+0.082 \mathrm{~A}-0.081 \mathrm{~B}-0.011 \mathrm{C}-0.27 \mathrm{AB}-9.205 \mathrm{E}-003 \mathrm{AC}+9.205 \mathrm{E}- \\
003 \mathrm{~B}-0.096 \mathrm{~A}^{2}-0.097 \mathrm{~B}^{2}-0.035 \mathrm{C}^{2}
\end{gathered}
$$

Final equation in terms of actual factors:

$$
\begin{aligned}
\mathrm{OD}= & 0.50837+0.081881 \mathrm{~A}-0.081132 \mathrm{~B}-0.010991 \mathrm{C}-0.27387 \mathrm{AB}-9.20457 \mathrm{E}- \\
& 003 \mathrm{AC}+9.20457 \mathrm{E}-003 \mathrm{BC}-0.095557 \mathrm{~A}^{2}-0.096566 \mathrm{~B}^{2}-0.035043 \mathrm{C}^{2}
\end{aligned}
$$

The analysis of fitting is shown in Table 4.

Table 4. The results of fitting second-order equations.

\begin{tabular}{cccc}
\hline Item & Data & Item & Data \\
\hline Std. Dev. & 0.11 & R-Squared & 0.8918 \\
Mean & 0.35 & Adj R-Squared & 0.7944 \\
C.V.\% & 32.32 & Pred R-Square & 0.4031 \\
PRESS & 0.70 & Adeq Precision & 9.418 \\
\hline
\end{tabular}

The above regression equations quantitatively described the relationship between the three independent variables $\left(\mathrm{A}, \mathrm{B}\right.$, and $\mathrm{C}$ ) on index and the overall desirability. The adjusted $\mathrm{R}^{2}$ for the predictive model is 0.8918 and the statistical test results of equation parameters are summarized in Table 4 . It is revealed that the experimental results adequately fitted the selected regression equations. The "Adj R-Squared" value of 0.7944 is not as close to the "Pred R-Squared" value of 0.4031, as one might normally expect. This may indicate a possible problem or a large block effect with the model and/or data. Things to consider are response transformation, model reduction, outliers, and so forth. "Adeq Precision" measures the signal-to-noise ratio and a ratio greater than 4 is desirable. The ratio of 9.418 indicates an adequate signal. This model can be used to navigate the design space. It can be used predictively the obtain response value of a random formula within the range and level of independent factors by regression equations.

To better comprehend the predictive three-dimensional graphs of the models in the results, the response surface diagrams of imperatorin lipid microspheres were created, as shown in Figure 1. The optimum formulation conditions were as follows: the amount of egg lecithin is $1.39 \mathrm{~g}$, the amount of poloxamer $188 \mathrm{is} 0.21 \mathrm{~g}$, and the amount of soybean oil for injection is $10.57 \mathrm{~g}$.

The recommended optimum conditions were used to test the suitability of the model equation for predicting the optimum response values. According to the model equation, the RSM optimization approach was used to determine the optimum conditions. Three batches of imperatorin lipid microspheres were prepared according to the optimized formulation. Table 5 listed the optimum ranges and the experimental and predicted values for the response variables under the test conditions, and the calculated percentage prediction error. As seen from Table 6, the prediction error of the response variables was found to vary between $2.4 \%$ and $4.3 \%$. The results of the verifying experiments were very close to the predicted values that were obtained from the optimization analysis using the desirability function with low prediction error, suggesting that the optimization was reasonable and reliable. 


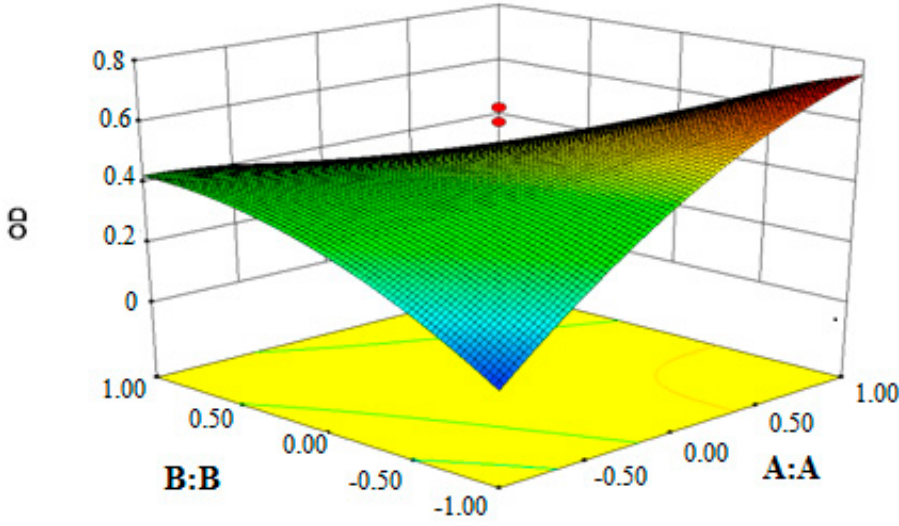

(a)

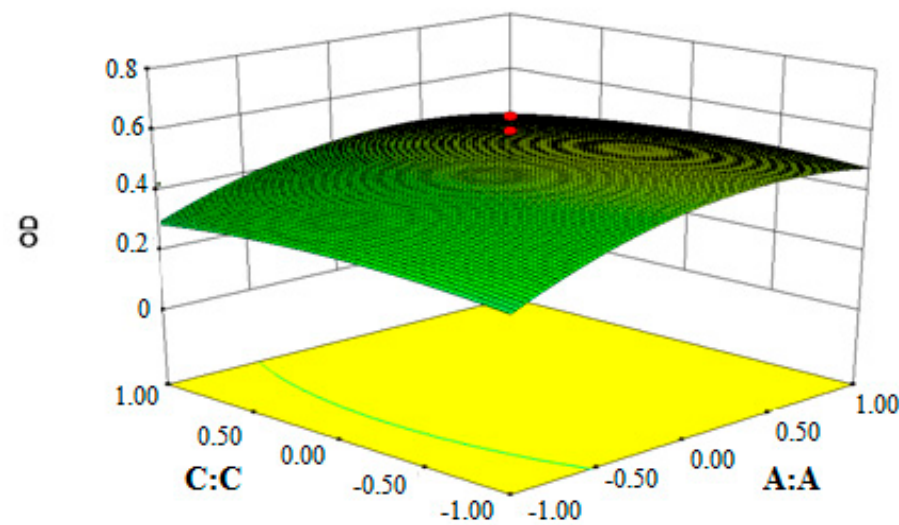

(b)

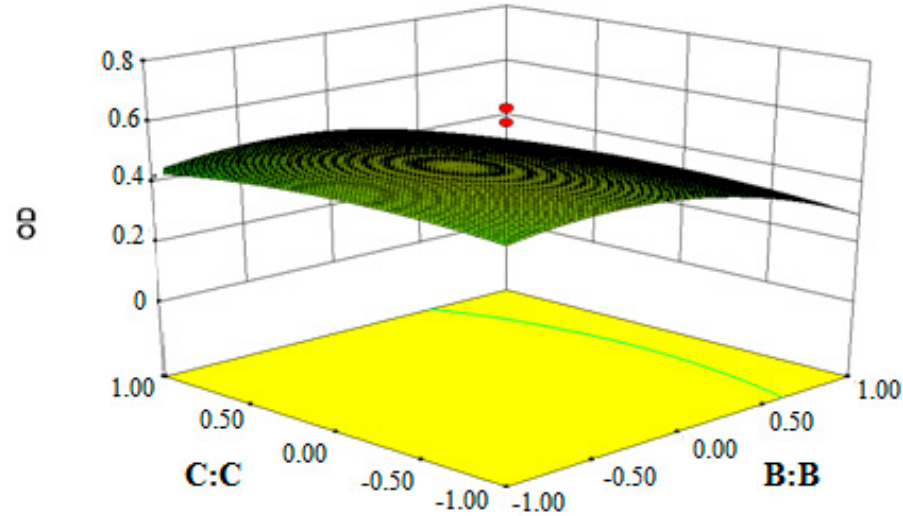

(c)

Figure 1. Response surface plot. (a) The effect of interaction of the egg lecithin and poloxamer 188 on OD value; (b) The effect of interaction of the egg lecithin and LCT/oil phase ratio on OD value; (c) The effect of interaction of poloxamer 188 and LCT/oil phase ratio on OD value.

Table 5. Constraints of factors and responses for optimization.

\begin{tabular}{ccccccc}
\hline Name & Goal & Lower Limit & Upper Limit & Lower Weight & Upper Weight & Important \\
\hline A: egg lecithin & is in range & 1.0 & 1.5 & 1 & 1 & 3 \\
B: poloxamer 188 & is in range & 0.1 & 0.6 & 1 & 1 & 3 \\
C: LCT/oil phase ratio & is in range & 0 & 50 & 1 & 1 \\
Responses: OD & maximize & 0 & 0.7286 & 1 & 1 \\
\hline
\end{tabular}


Table 6. The experimental and values for response (OD) along with percentage prediction error observed for the optimum test conditions.

\begin{tabular}{ccccccc}
\hline \multirow{2}{*}{ Batch } & A & B & C & \multicolumn{3}{c}{ OD } \\
\cline { 5 - 7 } & & & & Predicted Value & Experimental Value & Percent Prediction Error \\
\hline 20171101 & 1.39 & 0.21 & 10.57 & 0.7580 & 0.7286 & $3.8 \%$ \\
20171102 & 1.39 & 0.21 & 10.57 & 0.7580 & 0.7395 & $2.4 \%$ \\
20171103 & 1.39 & 0.21 & 10.57 & 0.7580 & 0.7251 & $4.3 \%$ \\
\hline
\end{tabular}

3.2. Drug Loading and Encapsulation Efficiency

The drug loading and encapsulation efficiency of three batches is reported in Table 7.

Table 7. Drug loading and encapsulation efficiency of imperatorin lipid microspheres $(\bar{x} \pm s, n=3)$.

\begin{tabular}{ccc}
\hline Batch & Drug Loading $(\mathbf{m g} / \mathbf{m L})$ & Encapsulation Efficiency (\%) \\
\hline 20171101 & 0.815 & 90.3 \\
20171102 & 0.836 & 91.2 \\
20171103 & 0.859 & 88.7 \\
Mean & $0.833 \pm 0.027$ & $90.0 \pm 1.27$ \\
\hline
\end{tabular}

\subsection{Particle Size and Zeta Potential Measurements}

The results of particle size and zeta potential are shown in Table 8. From the results, we can see that the imperatorin lipid microspheres have the traits of small size and narrow size distribution.

Table 8. Zeta potential and particle size of imperatorin lipid microspheres $(\bar{x} \pm s, n=3)$.

\begin{tabular}{cccc}
\hline Batch & Zeta Potential (mv) & Particle Size (nm) & PDI \\
\hline Carrier & $-44.9 \pm 1.20$ & $154 \pm 4.92$ & $0.157 \pm 0.04$ \\
20171101 & -43.1 & 169 & 0.114 \\
20171102 & -44.1 & 165 & 0.159 \\
20171103 & -43.5 & 169 & 0.142 \\
Mean & $-43.5 \pm 0.50$ & $168 \pm 1.73$ & $0.138 \pm 0.02$ \\
\hline
\end{tabular}

\subsection{Scanning Electron Microscopy (SEM)}

SEM images of the imperatorin lipid microspheres are shown in Figure 2. The imperatorin lipid microspheres were small homogenous vesicles with a bilayer lipid membrane.

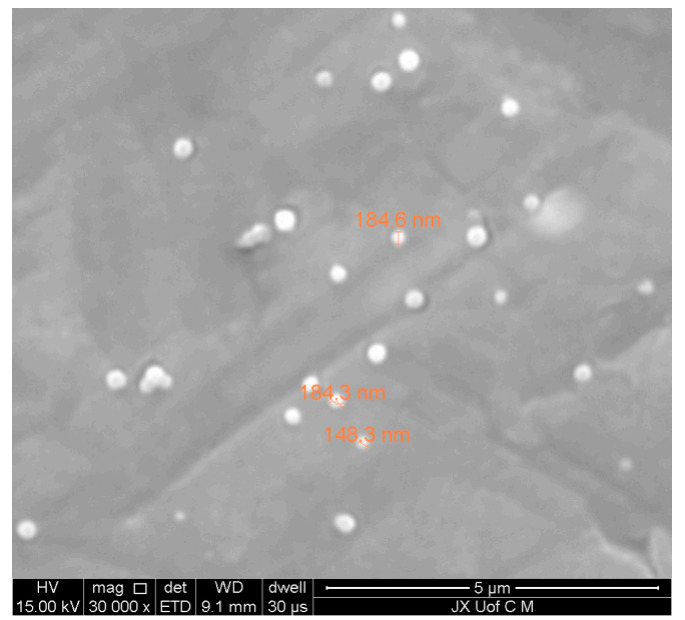

Imperatorin lipid microsphere

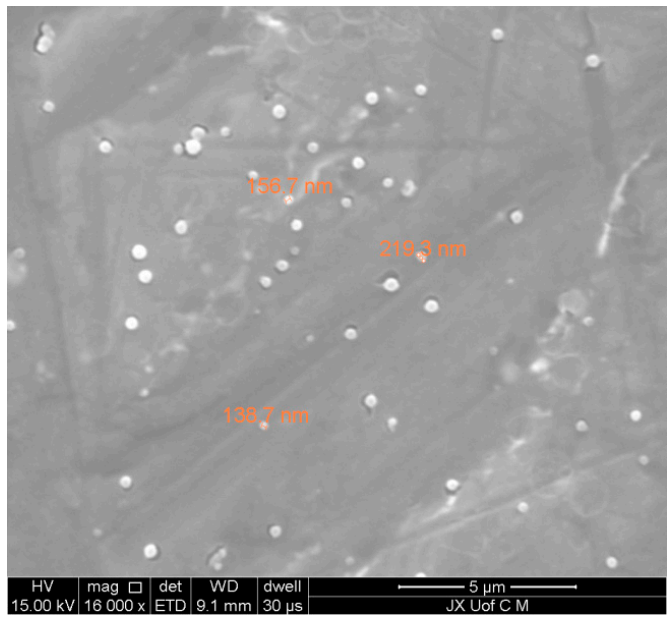

Blank lipid microsphere

Figure 2. Scanning electron microscopy of imperatorin lipid microspheres. 


\subsection{Pharmacokinetic Study}

A dose of $5 \mathrm{mg} \cdot \mathrm{kg}^{-1}$ of imperatorin lipid microspheres was injected intravenously into rat subjects. A dose of $50 \mathrm{mg} \cdot \mathrm{kg}^{-1}$ imperatorin was given by the means of intragastric administration. The pharmacokinetic parameters were calculated by DAS software. The mean plasma concentration-time curves are shown in Figure 3. The major pharmacokinetic parameters are listed in Table 9.

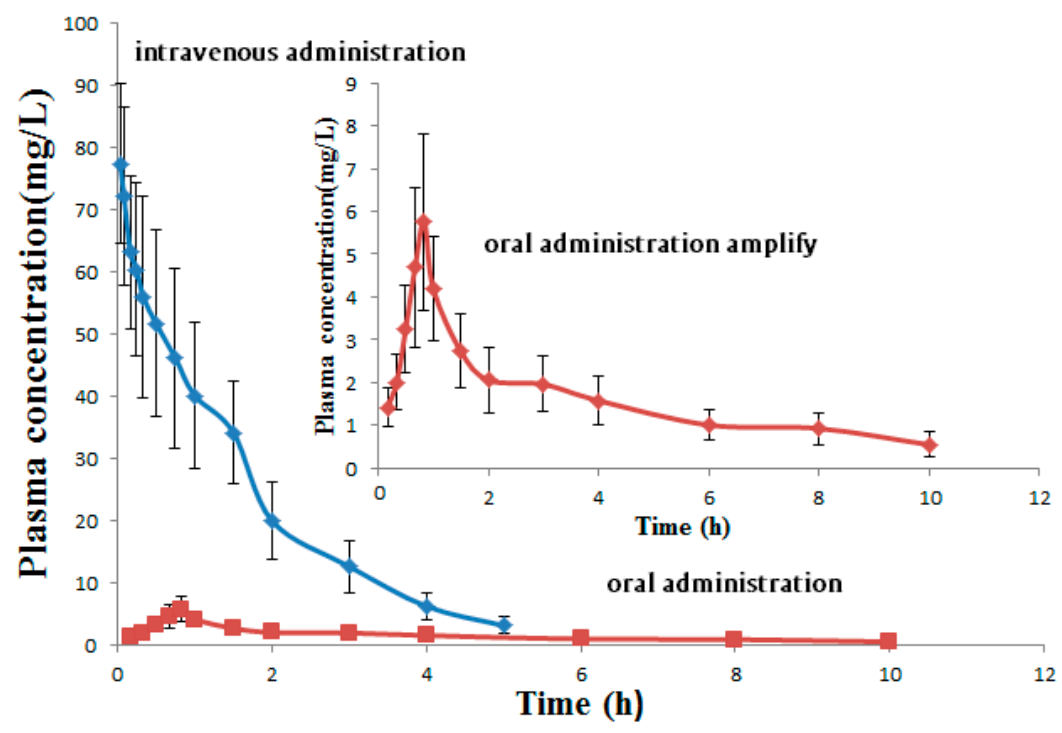

Figure 3. Mean plasma concentration-time curves after intravenous administration of $5 \mathrm{mg} / \mathrm{kg}$ imperatorin lipid microspheres and oral administration of $50 \mathrm{mg} \cdot \mathrm{kg}^{-1}$ imperatorin in rats.

Table 9. Main pharmacokinetic parameters of imperatorin after intravenous administration of $5 \mathrm{mg} \cdot \mathrm{kg}^{-1}$ imperatorin lipid microspheres and oral administration of $50 \mathrm{mg} \cdot \mathrm{kg}^{-1}$ imperatorin in rats (mean $\pm \mathrm{SD}, n=6$ ).

\begin{tabular}{|c|c|c|c|}
\hline \multirow{2}{*}{ Parameter } & \multirow{2}{*}{ Unit } & \multicolumn{2}{|c|}{ Route of Administration } \\
\hline & & Intravenous Injection & Oral Administration \\
\hline $\operatorname{AUC}(0-t)$ & $\mathrm{mg} / \mathrm{L} \cdot \mathrm{h}$ & $116.71 \pm 38.72 * *$ & $15.92 \pm 5.10$ \\
\hline $\operatorname{AUC}(0-\infty)$ & $\mathrm{mg} / \mathrm{L} \cdot \mathrm{h}$ & $121.24 \pm 40.01 * *$ & $19.04 \pm 6.57$ \\
\hline $\operatorname{AUMC}(0-\mathrm{t})$ & $\mathrm{h} \cdot \mathrm{h} \cdot \mathrm{mg} / \mathrm{L}$ & $160.74 \pm 60.78^{* *}$ & $56.13 \pm 18.01$ \\
\hline $\operatorname{AUMC}(0-\infty)$ & $\mathrm{h} \cdot \mathrm{h} \cdot \mathrm{mg} / \mathrm{L}$ & $189.92 \pm 70.59^{* *}$ & $105.49 \pm 31.13$ \\
\hline $\operatorname{MRT}(0-\mathrm{t})$ & $\mathrm{h}$ & $1.38 \pm 0.41^{* *}$ & $3.53 \pm 1.28$ \\
\hline $\operatorname{MRT}(0-\infty)$ & $\mathrm{h}$ & $1.57 \pm 0.51^{* *}$ & $5.54 \pm 1.95$ \\
\hline $\mathrm{t} 1 / 2 \mathrm{z}$ & $\mathrm{h}$ & $1.00 \pm 0.40^{* *}$ & $4.02 \pm 1.09$ \\
\hline Tmax & $\mathrm{h}$ & $0.03 \pm 0.01^{* *}$ & $0.83 \pm 0.24$ \\
\hline $\mathrm{CLz} / \mathrm{F}$ & $\mathrm{L} / \mathrm{h} / \mathrm{kg}$ & $0.04 \pm 0.01^{* *}$ & $2.63 \pm 0.98$ \\
\hline Cmax & $\mathrm{mg} / \mathrm{L}$ & $77.46 \pm 23.82 * *$ & $5.75 \pm 1.59$ \\
\hline
\end{tabular}

When compared with the oral administration of imperatorin, the $\mathrm{AUC}_{(0-\mathrm{t})}$ of imperatorn lipid microspheres significantly increased and the peak (maximum) plasma concentration $\left(C_{\max }\right)$ of imperatorin lipid microspheres $\left(77.46 \pm 23.82 \mathrm{mg} \cdot \mathrm{L}^{-1}\right)$ is much higer than that of imperatiorin $\left(5.75 \pm 1.59 \mathrm{mg} \cdot \mathrm{L}^{-1}\right)$. Upon IV administration at a dose of $5 \mathrm{mg} \cdot \mathrm{kg}^{-1}$, the time to peak (maximum) concentration $\left(\mathrm{T}_{\max }\right)$ was at $2 \mathrm{~min}$ after intravenous administration of imperatorn lipid microspheres in rats, and the time to peak (maximum) concentration $\left(\mathrm{T}_{\max }\right.$ ) was at $45 \mathrm{~min}$ after oral administration of imperatorin in rats, indicating that imperatorin lipid microspheres could be quickly detected in plasma. While imperatorin lipid microspheres was shown to have a short half-life (t1/2 $=1.00 \pm 0.40 \mathrm{~h})$ and a clearance of $0.04 \pm 0.01 \mathrm{~L} \cdot \mathrm{h}^{-1} \cdot \mathrm{kg}^{-1}$ than that of an oral imperatiorin $(\mathrm{t} 1 / 2=4.02 \pm 1.09 \mathrm{~h}, \mathrm{CLz} / \mathrm{F}$ $=2.63 \pm 0.98)$. The short half-life suggests that imperatorin lipid microspheres should be quickly 
metabolized in vivo and they should have a short duration of efficacy. The result suggested that we should investigate prolonging the half-life of imperatorin lipid microspheres.

\subsection{Effect of Imperatorin and Imperatorin Lipid Microspheres on MDA-MB-231 Cell Proliferation}

The results showed that the inhibition mediated by imperatorin and imperatorin lipid microspheres on MDA-MB-231 cell proliferation all had a positive correlation with the culture time (Figure 4). With increasing concentration of imperatorin or imperatorin lipid microspheres, the degree of inhibition of MDA-MB-231 cell proliferation improved correspondingly. When compared with the effect of imperatorin, the imperatorin lipid microspheres group had a stronger inhibitive effect on MDA-MB-231 cell proliferation than that of imperatorin.

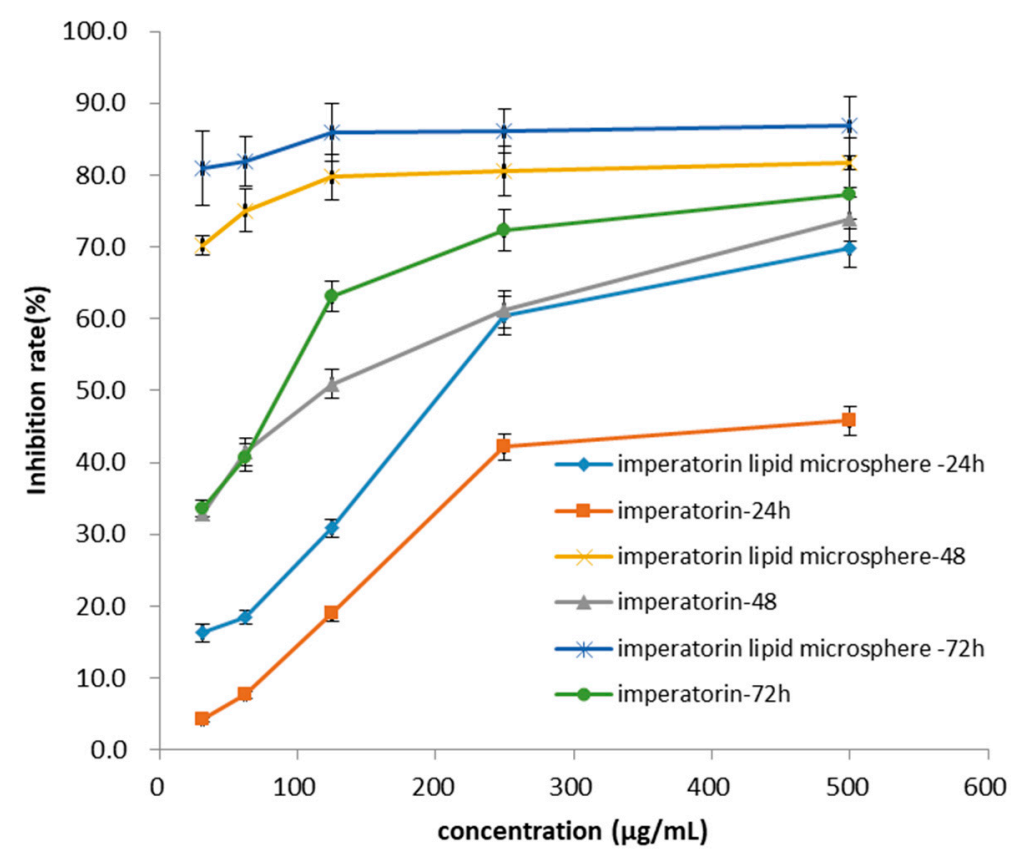

Figure 4. Inhibition cures of imperatorin and imperatorin lipid microspheres against MDA-MB-231.

\section{Conclusions}

The lipid microsphere is a good candidate for drug loading because of its safety, stability, and good biocompatibility, especially for those drugs with low solubility.

The central composite design-response surface method is an optimal design method that is used in the optimization of formulations due to its relatively small number of experiments required and high precision. According to the surface change, the three-dimensional effect of the surface chart could directly respond to the influence of factors on the survey index. Based on the overlying of better conditions chosen by multiple effects, the range of better conditions can be further reduced.

The optimal formulation was: egg lecithin-13.9 g, poloxamer $188-2.1 \mathrm{~g}$, and soybean oil-105.7 g. The particle size was $168 \pm 1.73 \mathrm{~nm}$, polydispersity index (PDI) was $0.138 \pm 0.02$, zeta potential was $-43.5 \pm 0.5 \mathrm{mV}$, drug loading was $0.833 \pm 0.027 \mathrm{mg} / \mathrm{mL}$, and the encapsulation efficiency was $90 \pm 1.27 \%$. The results showed that imperatorin lipid microspheres could significantly inhibit MDA-MB-231 cell proliferation. However, pharmacokinetic study of the imperatorin lipid microspheres showed that the half-time of imperatorin was very short. Thus, further studies should be conducted on how to increase its half-life duration and improve the residence time in blood.

Author Contributions: Conceptualization, X.L.; Data curation, X.C. and G.Z.; Investigation, C.W.; Project administration, X.L.; Resources, X.L.; Software, T.T.; Supervision, Z.L.; Writing-original draft, J.Z. and W.D.

Funding: This work was supported by a grant from the Key Laboratory of Modern Preparation of TCM of the Ministry of Education, Jiangxi University of TCM, and financially supported by the project of the Training Project 
of Young Scientists in Jiangxi Province (Nos. 20153BCB23019 and 2016BCB23034), the China Postdoctoral Science Foundation (2016M590606) and Postdoctoral Science Foundation of Jiangxi Province (2016KY49), the National Natural Science Foundation of Jiangxi Province (20161ACB21020), and the project on Cultivation of Medical Elite (GanboYingcai 555) ((2013)296).

Conflicts of Interest: The authors declare no conflict of interest.

\section{References}

1. Koziol, E.; Skalicka-Wozniak, K. Imperatorin-pharmacological meaning and analytical clues: Profound investigation. Phytochem. Rev. 2016, 15, 627-649. [CrossRef] [PubMed]

2. Choochuay, K.; Chunhacha, P.; Pongrakhananon, V.; Luechapudiporn, R.; Chanvorachote, P. Imperatorin sensitizes anoikis and inhibits anchorage-independent growth of lung cancer cells. J. Nat. Med. 2013, 67, 599-606. [CrossRef] [PubMed]

3. Luo, K.W.; Sun, J.G.; Chan, J.Y.; Yang, L.; Wu, S.H.; Fung, K.P.; Liu, F.Y. Anticancer Effects of Imperatorin Isolated from Angelica dahurica: Induction of Apoptosis in HepG2 Cells through both Death-Receptor- and Mitochondria-Mediated Pathways. Chemotherapy 2011, 57, 449-459. [CrossRef] [PubMed]

4. Huang, Z.P.; Shao, L.L.; Ruan, Y.P. Anti-tumor Effect and Mechanism of Imperatorin Enhances the Cytotoxicity of Cisplatin Osteosarcoma Cells. Chin. J. Mod. Appl. Pharm. 2015, 32, 1193-1197.

5. Zheng, Y.; Jiang, K. Antitumor effect of imperatorin enhances cytotoxicity of doxorubicin to HeLa cells. Chin. J. Pathophysiol. 2015, 31, 1578-1583.

6. Bqdziul, D.; Jakubowicz-Gil, J.; Paduch, R.; Glowniak, K.; Gawron, A. Combined treatment with quercetin and imperatorin as a potent strategy for killing HeLa and Hep-2 cells. Mol. Cell. Biochem. 2014, 392, $213-227$. [CrossRef] [PubMed]

7. Jakubowicz-Gi, J.; Paduch, R.; Ulz, Z.; Badziul, D.; Glowniak, K.; Gawron, A. Cell death in HeLa cells upon imperatorin and cisplatin treatment Cell death in HeLa cells upon imperatorin and cisplatin treatment. Folia Histochem. Cytochem. 2012, 50, 381-391. [CrossRef]

8. Badziula, D.; Jakubowicz-Gila, J.; Lanqner, E.; Rzeski, W.; Glowniak, K.; Gawron, A. The effect of quercetin and imperatorin on programmed cell death induction in T98G cells in vitro. Pharmacol. Rep. 2014, 62, 292-300. [CrossRef] [PubMed]

9. Wang, S.; Chen, Q.; Wang, L.; He, L. Develpoment and validation of a gas chromatography-mass spectrometry method for the determination of imperatorin in rat plasma and tissue: Application to study its pharmazokinetics. Anal. Sci. 2009, 25, 869-873. [CrossRef] [PubMed]

10. Han, F.; Wei, X.X.; Zhou, M.N.; Zeng, L.; Shu, J.C.; Yang, M. Research progress in traditional Chinese medicine injectable emulsion. Chin. J. New Drugs 2015, 24, 1980-1984.

11. Lin, H.; Xie, Q.; Huang, X.; Ban, J.; Wang, B. Increased skin permeation efficiency of imperatorin via charged ultradeformable lipid vesicles for transdermal delivery. Int. J. Nanomed. 2018, 13, 831-842. [CrossRef] [PubMed]

12. Pan, J.J.; Lu, W.; Li, C.H.; Wang, S.C.; He, L.C. Imperatorin sustained-release tablets: In vitro and pharmacokinetic studies. Arch. Pharm. Res. 2010, 33, 1209. [CrossRef] [PubMed]

13. Norden, T.P.; Siekmann, B.; Lundquist, S.; Malmsten, M. Physicochemical characterisation of a rug-containing phospholipid-stabilised O/W emulsion for intravenous administration. Eur. J. Pharm. Sci. 2001, 13, 393-401. [CrossRef]

14. Medina, J.; Salvado, A.; del Pozo, A. Use of ultrasound to prepare lipid emulsions of lorazepam for intravenous injection. Int. J. Pharm. 2001, 216, 1-8. [CrossRef]

15. Auriemma, G.; Mencherini, T.; Russo, P. Prilling for the development of multi-particulate colon durg delivery systems: Pectin vs. pectin-alginate beads. Carbohydr. Polym. 2013, 92, 367-373. [CrossRef] [PubMed]

16. Watts, P.J.; Illum, L. Colonic durg delivery. Drug Dev. Ind. Pharm. 1997, 23, 893-913. [CrossRef]

17. Rose, F.; Wern, J.E.; Inqvarsson, P.T.; van de Weert, M.; Andersen, P.; Follmann, F. Engineering of a novel adjuvant based on lipid-polymer hybrid nanoparticles: A quality-by-design approach. J. Control. Release 2015, 210, 48-57. [CrossRef] [PubMed] 
18. Xu, H.T.; Paxton, J.; Lim, J.; Li, Y.; Wu, Z.M. Development of a gradient high performance liquid chromatography assay for simultaneous analysis of hydrophilic gemcitabine and lipophilic curcumin using a central composite design and its application in liposome development. J. Pharm. Biomed. 2014, 98, 371-378. [CrossRef] [PubMed]

19. Varshosaz, J.; Ghaffari, S.; Khoshayand, M.R. Development and optimization of solidlipid nanoparticles of amikacin by central composite design. J. Liposome Res. 2010, 20, 97-104. [CrossRef] [PubMed]

20. Wang, M.; Chen, J.W.; Li, X. Study on antitumor activity of five Furanocoumarins from the root bark of Changium smyrnioides in vitro. Chin. J. Exp. Tradit. Med. Formul. 2012, 18, 203-205.

21. Chen, H. Apoptosis of human breast cancer cell line MCF-7 induced by orbixin. Zhejiang Pract. Med. 2015, 20, 177-179.

22. Yang, X.W.; Xu, B.; Ran, F.X.; Wang, R.Q.; Wu, J.; Cui, J.R. Inhibitory effect of 40 Coumarins Compounds against growth of human epidermal carcinoma a cell line A432 and human mammary cancer cell line BCAP in vitro. Mod. Chin. Med. 2006, 8, 9-10.

23. Wang, Y.; Tang, X.; Cai, C. Study of tacrolimus-loaded lipid microsphere preparation. Chin. J. Pharm. 2014, 12, 167-176.

24. Liu, A.; Chen, H.; Tang, X. Preparation and physical stability of astragaloside IV lipid microspheres for injection. Chin. J. Pharm. 2009, 7, 290-298.

25. Pharmacopoeia Commission of the Ministry of Health of the People's Republic of China. Pharmacopoeia of the People's Republic of China; China Medical Science Press: Beijing, China, 2015.

26. Yang, S.Y.; Chen, J.Y.; Zhao, D.; Han, D.; Chen, X.J. Comparative study on preparative methods of DC-Chol/DOPE liposomes and formulation optimization by determining encapsulation efficiency. Int. J. Pharm. 2012, 434, 155-160. [CrossRef] [PubMed]

27. Wu, W.; Cui, G.H.; Lu, B. Optimization of multiple evariables: Application of central composite design and overall desirability. Chin. Pharm. J. 2000, 35, 530-533.

(c) 2018 by the authors. Licensee MDPI, Basel, Switzerland. This article is an open access article distributed under the terms and conditions of the Creative Commons Attribution (CC BY) license (http:/ / creativecommons.org/licenses/by/4.0/). 